\title{
Learning and Knowledge Transfer in Global Modular Production: A Developing Country View $^{* *}$
}

\author{
Gustavo Guzman \\ Griffith University, Australia \\ g.guzman@griffith.edu.au \\ John Wilson \\ University of Liverpool, UK
}

** Paper accepted to be published as book chapter in Buckley, P. (Ed.) The Global Factory, forthcoming. 


\title{
Learning and Knowledge Transfer in Global Modular Production: A Developing Country View
}

\author{
Gustavo Guzman \\ Griffith University, Australia \\ John Wilson \\ University of Liverpool, UK
}

\section{Introduction}

The contract manufacturing industry has been reshaped to accommodate the way in which most of the world production and consumption of electronics is being shifted to the developing world, and in particular to the BRIC [Brazil, Russia, India and China] economies. The BRIC nations are expected to be among the five largest world economies by 2050. Those countries are expected to represent more than $40 \%$ of the world population and to generate a combined Gross Domestic Product of \$73 trillion during the next 40 years (Pick, 2009). The importance of BRIC nations was being confirmed in the 2008-2009 world financial crises, because they were the only economies that continued to record positive growth rates. Moving world electronics production to the BRIC economies, however, is by no means simple, since both product design and process technologies have been devised in more highly developed economies, while parts and components producers are scattered around the globe, making logistics and distribution activities increasingly complex.

Simultaneously, the further opening of economies and proliferation of trade agreements is promoting a continuous restructuring of whole production networks core firms, partner firms, specialized suppliers, contractors and service providers creating virtual networks of value creation (Berger and Dore, 1999). As a result, new partnership strategies, new external relations among companies (contracts, alliances, equity purchases, and outright ownership) and supporting policies are emerging to integrate producers, suppliers and customers within and among different economies 
(Galbraith, 2000). Individual companies have also been redefining their core competencies and negotiating their strategic role in order to build capabilities across the whole production chain (Bartmess and Cerny, 1993; Ferdows, 1997). This means that there has been an evolution to what Hedlund (1986) has termed heterarchical tendencies, associated with global collaboration, while at the same time reinforcing hierarchical co-ordination. Whilst there are a myriad range of questions waiting for answers, this chapter discuses learning and knowledge transfer (L\&KT) processes in Global Modular Production (GMP) from a developing country perspective. Specifically, this paper aims at a panoramic snapshot of how different units of the same GMP network, located in different economies, coordinate and integrate their L\&KT activities. Focussing at the inter-unit level, the following questions will be answered:

- What are the processes developed in GMP to support L\&KT of explicit forms of knowledge?

- What are the processes developed in GMP to support L\&KT of tacit forms of knowledge?

- How knowledge issues are connected to organisational issues?

Two reasons justify this study. Firstly, while studies about knowledge transfer and learning in MNC do exist (e.g. Simonin, 2004; Bjorkman et.al., 2004, Minbaeva, 2007; Saliola and Zanfei, 2009), still further research focussing on the specific case of modular production units located in developing economies (c.f. Foss and Pedersen, 2004) is necessary. Secondly, GMP represents an exemplary case of international manufacturing network systems as it possesses a high degree of both geographical dispersion and interdependent coordination, (Shi and Gregory, 1998) providing a major challenge when establishing L\&KT processes.

In the next section, key GMP concepts are explained. Section three outlines a brief examination of the learning and knowledge transfer literature in GMP. In the following section, the empirical evidence is presented, while in the concluding section an attempt to answer the main research questions is made. 


\section{Global Modular Production: Basic Concepts}

Learning is defined as the processes by which skills and knowledge are acquired by individuals and, through them, organisations. There are, however, different forms of learning related to the nature of knowledge that is being acquired (Bell, 1984). In this paper, the term 'learning' is used for the cases of acquiring knowledge that is mostly tacit, while the term 'knowledge transfer' is applied to the case of acquiring knowledge which is mostly explicit. Because learning largely depends on experience, learning-by-doing methods seem adequate. In the case of knowledge transfer, however, because knowledge and skills to be acquired are explicit, a myriad range of methods can be used.

Global manufacturing can be defined as 'networks of business serving the businesses' chosen markets in a coordinated and optimized way' (Shi and Gregory, 1998: 212). Global companies therefore are blends of units for product lines, with country subsidiaries and business functions which dynamically move among and between different national settings (Galbraith, 2000). The concept of Global Modular Production Networks is crystallised in the Contract Manufacturing (CM) arrangements existing in the electronics industry. Under CM arrangements, the whole industrial chain is divided into two parts. One part, the customers (usually referred to as OEMs - original equipment manufacturers), are responsible for design, marketing, and sales. The second part, the manufacturing and logistics services, is performed by contract manufacturers. This form of GMP combines the idea of economies of scale (Chandler, 1990) with the concept of core competencies (Hamel and Prahalad,1994), in order to increase the efficiency of the whole network by lowering production costs and simultaneously supporting product innovation, allowing OEMs to focus on highvalue-added activities such as product design and new process technology development. By outsourcing manufacturing activities, OEMs transform their manufacturing costs from fixed to variable, which implies that GMP absorb OEMs' customers' variable demand, which in turn requires them to develop highly efficient manufacturing plants in order to meet mix and volume flexibility demands (Sturgeon, 2002). 
The efficiency of GMP networks, therefore, depends to a significant extent on the quality of co-operative relations developed in different organisational units. Crucially, it is important to remember that OEMs and CMs perform three different tasks separately, namely, product design, manufacturing and marketing/sales. Despite the significant differences in the type and nature of tasks performed by CMs and OEMs, success depends on the convergence of work methods, organizational structures and organizational goals. Thus, the co-ordination of the whole productive chain becomes a key issue, as design and manufacturing activities are concentrated, yet performed by different organizations (in different locations) and, at the same time, marketing and sales are de-concentrated (Zarifian, 1999). This means that knowledge acquisition and transfer are crucial for GMP network competitiveness.

Manufacturing activities in this type of GMP are deployed under the logic of industrial services (Zarifian, 1999). Electronics GMP arrangements not only have features of both industrial and service sectors, but also follow different logics which are hard to combine. While the industrial logic follows mass production/low cost/standardised product/rigid technological processes and hierarchical employeeemployer relationships, the service logic pursues small and medium volumes/customised production/flexible technological processes and co-operative type employee-employer relationships. In other words, GMP arrangements need to develop service type capacities and competencies, such as mix, volume and new product flexibility (c.f. Suares, Cusumano and Hine, 1995), in order to fulfil customers' product differentiation needs, while at the same time carrying out manufacturing activities with the same continuity/stability and low costs as mass production processes. This implies further logistical, organisational and technological complexity, which means that GMP need to build new personnel and organizationrelated competencies, as well as create efficient coordination mechanisms in order to diffuse company knowledge. ${ }^{1}$ Thus, this paper focuses on the learning and knowledge

\footnotetext{
${ }^{1}$ Added to the above logistical and organisational complexity is technological complexity. The assembly of electronic based products in small batches is complex, since they have interaction complexity and are non-decomposable. Interaction complexity results from multiple interactions among product functions (component or subsystems). For example, a printer has a high number of components with extensive intercomponent (or subsystem) interfaces. A printed circuit board (PCB), on the other hand, cannot be separated into its components without degrading performance, so it is nondecomposable (Khurana, 1999).
} 
transfer (L\&KT) mechanisms and its associated organisational processes used at interunit level, considering the different type of knowledge and the different types of GMP networks.

Given these challenges, there is clearly an increased need to design organizational architecture that supports co-ordination, co-operation both within and among organizational units, as well as a need for the development of mechanisms to manage company knowledge. Higher product variety, shorter life-cycle of products, a higher mix and volume, as well as flexibility to meet the demands for new products, result in higher interdependency among organizational units (OEM and CM). In turn, this increase calls for an improvement in communication and knowledge flow. Matrix structures, accompanied by lateral integration mechanisms, such as mutual adjustment, formal groups and integrator roles and/or departments, need to be purposely designed in order truly to differentiate and integrate organizational units inside the whole production network (c.f. Galbraith, 2000; Nohria and Ghoshal, 1997).

Finally, the extent to which knowledge is created, transferred and applied varies, depending on the type of GMP. Saliola and Zanfei (2009) have proposed three types of GMP. In the first, knowledge is mostly codified and flows in one direction only. In the second, the supplier of knowledge provides, for example, product design and quality standards to be followed by the manufacturing unit. In the third, the buyers disseminate specialized competencies and involve the supplier in R\&D and knowledge development.

\section{Learning and Knowledge Transfer in Global Modular Production}

L\&KT between units of GMP networks not only seems to be crucial for competitiveness (Buckley and Casson, 1976), but also it can be complex and problematic (Macharzina, Oesterle and Brodel, 2000). It is complex because knowledge is multidimensional. Knowledge has simultaneously explicit and tacit 
features in different extents (Polanyi, 1983). On the one hand, knowledge transfer and learning of the explicit dimension of knowledge is direct and simple, since it can easily be articulated and codified in rules because it is impersonal and has low levels of context embeddedness (Davenport and Prusak, 1998). On the other hand, learning the tacit dimension of knowledge is difficult, since tacit knowledge is strongly dependent on personal judgements that are socially constructed, situated and embedded in practices located in specific contexts (Wenger, 1998; Orlikowski, 2002; Tsoukas, 2005). This means that the degree of complexity to transfer knowledge depends to a significant extent on the nature of the knowledge being transferred. At one extreme, technical knowledge that is usually well codified can be transferred using norms, books and protocols that in turn can be captured, stored and diffused by means of information systems. At the other extreme, knowledge dealing with 'soft' issues (Guzman and Wilson, 2005a) requires knowledge transfer mechanisms centred on people. That is, formal and informal face-to-face communication and practical demonstration of activities supplemented with contextual information, constitute the central mechanism to share and learn tacit forms of knowledge. In the middle of those extremes, organisational knowledge, which possesses both explicit and tacit features, required a combination of knowledge transfer mechanism that deal with those dimensions.

Learning \& knowledge transfer can be problematic because of the complexity of cross-border organizations (Galbraith, 2000), the existence of conflicting goals inside and between organizations (Perrow, 1979), the level of trust between sending and receiving units, the incentives that network units have to share knowledge (Child and Faulkner, 1998), the limits of human rationality (March and Simon, 1958), the proportion of tacit knowledge embedded in knowledge being transferred (Ancori, Bureth and Cohendet, 2000), and the degree of uncertainty of the receiving unit's context (Stacey, 1996). The transfer of organizational knowledge templates, for example, is site-specific and part of its content is abstract. On the one hand, in order to ease the coordination of activities and minimize transaction costs between branches located in different economies, organizational concepts are standardized and 'packaged' with different degrees of abstraction in order to be applied across borders (Lillrank, 1995). Nevertheless, since branches do not have, necessarily, the same production technologies, work organisation, factory layouts, work flow and quality of 
human resources, the 'adaptation' process - even manufacturing the same products for similar customers - is difficult because it is site-specific. As Fruim (1997: 162) noted, 'the nature of factory know-how is not contained in manuals but is found instead in practice and experience. This history is embodied in factory-specific, faceto-face relations, on-the-job training and in people-based, site-specific knowledge’.

The L\&KT literature can be grouped into organisational and inter-organisational (network) theories. While there is a proliferation of L\&KT theories from the organisational perspective (e.g. Leonard, 1995; Dougherty, 1999; Walsh and Ungson, 1991; Argote and Ingram, 2000; Zollo and Winter, 2002), there are few knowledge transfer frameworks that focus on international networks. L\&KT theories focussing at the organisational level suggest that senders' and receivers' absorptive capability (Hansen, 1999), technology characteristics (Argote and Darr, 2002), degree of context similarity (Dixon, 2000), and type of knowledge - tacit or explicit - play a crucial role in the knowledge transfer process. The central point of their argument, however, is that knowledge transfer processes are directly related to: (i) the match between type of knowledge and knowledge transfer mechanism used; and (ii) the development of capabilities to devise the required knowledge transfer mechanisms. Those capabilities involve the simultaneous use of people and technology-centred mechanisms to transfer knowledge (c.f. Olivera, 2000 and Prencipe and Tell, 2001). While these theories seem to deal adequately with the main dimensions of knowledge transfer, they assume unitary strategies and central hierarchies, something that does not necessarily occur in GMP networks.

L\&KT theories focusing at the international network level are few. Buckley and Carter (1999, 2004) posited that because in international networked organisations knowledge is dispersed, they need to orchestrate knowledge residing in different parts of the network. This orchestration is provided through the combination of three forms of knowledge. The first is called 'additive complementarity' and happens when knowledge in one part of the firm has direct relevance to actions in other parts of the firm. The second is 'sequential complementarity' and occurs when knowledge from one firm member is inputted for the acquisition of knowledge in other parts of the firm. The last one is 'complex complementarity', referring to the case of two firms performing significant interaction in order either to acquire or transfer knowledge. 
Buckley and Carter (2004) suggest that those three types of knowledge complementarity are adequate for different environments. While additive complementarity is adequate for networks performing in less volatile environments, sequential and complex complementarity are more adequate for networks performing in more dynamic environments.

Contrary to the smaller number of inter-unit L\&KT theories, there is an increasing stream of empirical studies focusing around cross-border knowledge transfer and acquisition. Nohria and Ghoshal (1997) suggested that slack distribution, degree of autonomy of subsidiaries, socialization mechanism used to bind people along the network, the use of multiple normative coordination mechanisms, and the quality of communication flows explain the extent to which cross-border networks facilitate the necessary knowledge creation and transfer among units. Lyles and Salk’s (1996) empirical study in international joint ventures found a direct relation between structural organizational mechanisms, such as training, articulated goals and capacity to learn, and the extent to which organisations learn; tacit managerial knowledge acquisition has greater positive impact on outcomes than technical knowledge acquisition; differences in IJV ownership structure affect knowledge acquisition and national culture differences are not always impediment for knowledge acquisition.

In a special issue of the Journal of International Business Studies, Foss and Perdersen (2004) stressed the lack of understanding of the causal mechanism to transfer knowledge in MNEs, contextual factors and the relations between knowledge processes and organisational factors underpinning them. Attempting to overcome some of those challenges, empirical research pointed out that knowledge transfer is a function of the balance of power between headquarters and subsidiaries (Mudambi and Navara, 2004). Simonin (2004) advanced a knowledge transfer model that includes learning capacity, knowledge ambiguity and tacitness to explain knowledge transfer in strategic alliances. Dhanaraj, Lyles, Steensma and Tihanyi (2004) developed the concept of relational embeddedness to explain social relationships between foreign parent and IJV as a determinant of knowledge transfer. Their empirical study suggested that relational embeddednes is more important in transferring tacit forms of knowledge than for transferring explicit forms of knowledge. 
Later empirical studies have further detailed processes of L\&KT in GMP. Minbaeva (2007), for example, noted that successful knowledge transfer is not only function of the features of knowledge, but also a function of the features of individuals (senders and receivers) involved and context. Evangelista and Hau (2009), in their investigation about the impact of organisational context on the acquisition of explicit and tacit knowledge in IJV, found that cultural differences of partners is not a key inhibitor of knowledge acquisition. Saliola and Zanfei's (2009)'s study of knowledge transfer in global value chains found that the GMP type that are characterised by greater knowledge transmission is positively associated with the intensity of multinational presence in the local market, with the efforts of MNCs to adapt to local context and with competencies of domestic suppliers.

Kotabe, Dunlap-Hinkler, Parente and Mishra’s (2007) research stated that international knowledge transfer benefits innovative performance in an inverted Ushaped relationship. That is, at low and moderate levels of international knowledge improves its innovative performance while at higher levels of international knowledge content, there is a diminishing returns to transferring knowledge from overseas. Hong and Nguyen (2009) studied the mechanisms to transfer knowledge used by MNCs. They found that the appropriate choice of knowledge transfer mechanisms is important to distribute and adapt knowledge relevant to the local environment. Higher levels of knowledge embeddedness requires knowledge translation, sense-making and co-participation, while transferring knowledge with low moderate levels of local embeddedness requires conventional mechanisms such as formal training, meetings and job rotation.

Considering the above studies were developed in GMP networks possessing different governance configurations, still they show agreement on key aspects of the L\&KT process, such as the use of multiple normative integration mechanism, quality of communication flows, clear articulation of goals for the whole network, the recognition of the need to acquire/develop tacit managerial knowledge and the required match between. However, a series of key aspects of inter-unit L\&KT processes still demand further empirical studies, since no conclusive evidence was shown. For example, the role of context and culture is still a controversial point. 
In this study, following Westney (1999), the logic of knowledge transfer is understood as the combination of two complementary perspectives. Firstly, there is: the strategic design view that sees the transfer of organisational structures, processes, practices and routines as key organisational processes deployed in order to support knowledge acquisition and transfer, that in turn supports company competitiveness. The social construction perspective, on the other hand, suggests that transferring organisational structures, procedures and routines is not enough successfully to transfer knowledge. This view suggests that it is necessary to consider different interpretations that one concept or organisational model might have, as well as crucial taken-for-granted institutional behaviours and ways of thinking that are site specific and tacit in nature.

\section{Research Strategy and Setting}

Because L\&KT processes involve both explicit and tacit forms of knowledge, this research uses qualitative research methods. This involves the use of the case study method drawn from action research, a highly adequate approach since the object of research does not have a well established theoretical base and contextual conditions seem to be important (Yin, 1981).

Early studies (Guzman and Lopez, 2000) on the macro institutional factors shaping Brazilian GMP pointed to mixed results. On the one hand, the existence of consistent fiscal incentives to assemble electronics products from imported component, Moreover, the presence of a well qualified cadre of technicians and managers supports the further development of the electronics GMP industry in Brazil. On the other hand, complex custom laws and outdated practices as well as the long term separation between industry, training and workers' associations hinder the further development of this industry. Complementing this work, Guzman and Wilson (2005b) studied micro-level organisational practices applied by Brazilian GMP. They found that the implementation of 'continuous improvement' was a complex learning process that involved both behavioural changes and careful design of organisational structures and processes. The present study aims at further understanding the relationship between organisational processes and the L\&KT mechanisms applied in order to improve manufacturing processes. 
This study is based on an 1800-employee Electronics Contract Manufacturing plant located in Brazil, which is one of the many plants owned by a large United States based MNC (called here HQ). In early 2009, formal and informal in-depth interviews were conducted, supported by plant visits and direct observation of manufacturing processes, as well as organisational and management practices. The plant's operations manager and a business unit manager were interviewed. At BR [not its real name], printed circuit board (PCB) mounting, testing and final assembly, as well as procurement and purchasing of components, are the main activities. PCB operations are hybrid, since almost all PCBs use both automated surface-mount technology (SMT) and labour-intensive placement-through-hole (PTH) technology.

Despite the standardised nature of its products and processes, manufacturing operations in this industry are complex, because of the large number of precision parts involved that are manufactured by third parties, the dynamic nature of products with ever-evolving models, and the development of new families. In the last three years, for example, five new printers and eight new point-of-sale (POS) models were introduced, together with a totally new product.

Contextual factors influence micro level practices. Roughly speaking, while the Brazilian industrial structure has been classified as fragile (Katz, 2000), an indigenous technological capacity was installed in selected areas and the general skill level of operative workers is low-medium. Despite real wage increases in the last decade, the general pattern of wages is low and a highly uneven income distribution exists. This profile, together with a stable economic growth in the last decade, partly explains the current stable socio-political environment (Dalhman and Frishtak, 1993; Amann and Baer, 2002). Those factors contributed to the development of 'culturally-rooted' managerial features that might either enable or block organizational knowledge transfer (Wood and Caldas, 2002; Amado and Brasil, 1991). On the one hand, the institutionalisation of short-term vision, low individualism, good communication skills and ambiguous behaviour makes easier the acceptance of foreign inter-firm arrangements. The fascination with the foreign (persons, cultures and artefacts) favours the development of alternative informal behaviours in order to minimise other uncertainties. These features support knowledge transfer. On the other hand, 'highpower distance', personal links, loyalty to persons (peers or superiors), rather than to 
the organization, as well as conservative management thinking, combined with shortterm business logic and the institutionalized low-wage industrial culture, might block the deployment of L\&KT practices.

From the macro-economic perspective, it should be noted that the exchange rate is a crucial element to define the degree of competitiveness in this industry. As most of HQ's factories have similar productivity ratios, the key differential competitive factor becomes country exchange rate. In the Brazilian case, for example, if one USD is equal or lower than 2.30 BRL, it becomes unfeasible to export. In Brazil, there is a well established policy of subsidizing the electronics sector, in order to ensure its survival for both generating jobs and minimizing the use of foreign reserves. According to our interviewees, imported electronic products pay approximately $20 \%$ more in taxes than locally assembled products.

\section{L\&KT in Global Modular Production-- A Developing Country Perspective}

The electronics CM industry is a mass-production industry which has two very clearly defined stages: printed-circuit-board (PCB) and assembly. PCB manufacturing is a highly standard process. The large majority of required PCBs are manufactured following the same production process independently of the final product. Knowledge acquisition and transfer about manufacturing is usually related to the acquisition of new assembly technologies; the application of lean manufacturing techniques; the implementation of quality control related systems; and lately environmentally-related technologies such as reverse engineering and 'green' logistics. Product-related improvements do exist, but they are designed by customers. Thus, process improvement related knowledge acquisition is a key capability in this type of industry.

BR has developed two complementary sets of organisational processes to drive actively the flow of knowledge across manufacturing units. The first set of processes directly promotes L\&KT activities and involves conventional training, specifically web-based training with experts and face-to-face learning-by-doing learning 
processes. The second set of processes that actively support L\&KT activities targeting the improvement of existing processes are embedded in BR's matrix organisational structure, to be outlined below. All information detailed in the next two sub-sections titles is a summary of the results of the data collection process, unless the contrary is specified.

I. BR's L\&KT processes are deployed in three complementary forms: first, through conventional in-house training practices; second, through training via the web; and third, by providing in-depth training to one person or small teams who, in turn, disseminate the acquired knowledge. These three forms are applied depending on the extent to which knowledge is more tacit or explicit. When knowledge to be acquired is well known in BR (that is, it was or is currently applied in other units) and it has already been codified in procedures or software, conventional training programmes are used. If conventional training is not enough, additional support is provided by current users via web meetings. Finally, when knowledge to be acquired is mostly new to BR personnel, when there is no ready-made codified knowledge, and when knowledge to be acquired has significant tacit components, face-to-face as well as learning-by-doing mechanism are applied.

According to the business unit manager, BR is very well prepared to deal with explicit forms of knowledge. Conventional training, 'multipliers', standardization of processes and organizational structure are the most used knowledge transfer and learning mechanisms used. Another mechanism used to transfer explicit forms of knowledge is BR University. BR possesses a formidable formal system to promote L\&KT in the form of its own university, a sophisticated repository of procedures, information and knowledge in most functional areas, including design, production processes, engineering, logistics, as well as management and operations improvement tools. Each position has a well-defined standard training system. This training can be done either at a self-paced level, through either on-line or in symposiums, in which lectures are delivered 'live' via the web at pre-determined times. While this form of training is comprehensive and seemed well structured, it deals only with explicit forms of knowledge. 
Secondly, there is training via the web. This training is delivered by experienced BR personnel, located in other units/countries who are already expert users of the specific technology. The aim is to support the transfer of knowledge that is partly explicit and partly tacit.

The third form of L\&KT deals with knowledge that is mostly tacit. BR dealt with tacit forms of knowledge in two ways: firstly, by using face-to-face interaction between interested parties. This means that, if required, BR personnel will travel to locations where the required knowledge is available and participate in lengthy on-the-job training. Another alternative is through the use of so-called 'multipliers', namely, skilled personnel who receive on-the-job knowledge in the premises of the customer or other BR unit. This in-depth, face-to-face learning-by-doing training to one person or small team enables learning of tacit forms of knowledge that otherwise cannot be learnt by conventional training means.

Secondly, in the case of totally new products (this is, roughly, in $10 \%$ of the cases), knowledge required is mostly tacit and BR is aware that some tacit knowledge cannot be explicated. It must be noted that different aspects of the knowledge to be acquired do have different degrees of tacitness. Electronics knowledge, for example, is universal knowledge that is usually codified in well-known theories and concepts. This type of knowledge is transferred to BR personnel through conventional training sessions. On the other hand, there is a portion of knowledge to be acquired that possesses significant intangible dimensions. This knowledge is related to safety features, performance of particular parts and/or components, and production process 'reliability'. This knowledge, according to the manager, because it is intangible, can only be developed during experience gained in day-to-day operations. HQ and BR are well aware of this problem. In this case, because BR is aware of the limitations to promote L\&KT by conventional means, BR relies on experience building for this task. Bell and Albu (1999) noted that knowledge accumulation, rather than just production systems, are needed to support competitiveness in developing countries. Knowledge accumulation happened in different forms. For example, BR personnel can be trained on a new process on a customer's premises using face-to-face experience combined with on-the-job training. 
It is also noteworthy that the definition of the production plan for a specific customer is developed based on a formal process which is explicit and embedded in software. The system that has different stages performs calculations and offers concrete advice. According to the managers, while this advice is valuable, usually it is not taken at face value, since experienced people often know specific pieces of particular information for example, about competitors, key suppliers or what other HQ units around the world are doing — that might change the final decision. As one manager noted:

I for example, cannot lock on a specific date with a customer [to deliver an order] if I know an specific supplier has problems with a particular part and will be unable to meet the due date".

A similar situation usually occurs when making the decision to evaluate required manpower for a specific production line:

“... we do have in place all tools and software to get information and make the decision. However, at the end of the day, most of the times, our decision is made based on our intuition. We see that the figure suggested by our tools simply does not make sense”.

Experience building is also crucial for dealing with 'soft issues' (Guzman and Wilson, 2005) that contain significant tacit components. Knowing customers' operations and customers' requirements, for example, is a 'soft issue' that BR recognises as crucial for business success. As one manager stated:

knowing people in the organization [customer] is crucial ... I know [customer's] all stages of product development, including design, validation, engineering development and engineering manufacturing... I know the customer's market and distribution channels ... because this customer does not keep their processes and procedures well documented, knowing people is key ... inter-personal relationships are important because through them I got access to information that otherwise, I will not get.

In the case of introducing new products or totally new processes, different KT mechanisms are applied. In this case, face-to-face, on-the-job training and co-location 
mechanisms are the norm. In the case of a new customer, for example, BR's engineering, materials and production personnel visit the customer site in order to learn their formal and informal procedures and practices regarding operations, logistic and purchasing. Back at the Brazilian unit, the managerial team adapt the customer's procedures and practices to local conditions of operation.

A similar situation occurs when a new supplier is developed. Key managerial and engineering personnel are sent to the supplier in order to observe, check and comprehend the new supplier's key procedures and practices. The operations manager said that face-to-face communication and direct observation are the only way to provide an adequate check on the new supplier's capabilities, because suppliers not only supply parts and components, but time (delivery) and consistency (of quality) variables are crucial in the electronics industry.

Finally, in the case of introducing totally new machinery, an engineer was sent to Japan, to the production site of new automated manufacturing machinery, for a threemonth period in order to learn the machine's operation, maintenance and programming. This period allowed not only learning the technical side of the equipment, but most importantly, knowing and establishing relationships with key Japanese technical staff who play a crucial role for future technical assistance that goes beyond formal protocols and procedures.

II. BR's matrix organisational structure is composed of a functional and a production/customer dimension. The former includes typical functional areas, such as manufacturing, engineering, planning and purchasing that support manufacturing cells. The latter involves 'manufacturing cells' that are associated with specific customers. Daily operations of manufacturing cells are supervised by a 'business unit coordinator', while strategic decisions for specific customers are made by 'business unit managers'. L\&KT occurs through the main dimensions of BR's (and HQ's) matrix structure.

First, L\&KT is supported by the customer dimension of the matrix organisational structure. Business unit managers (BUMs) are responsible for specific large 
customers, directly reporting to the Global BUM, and are loosely coupled with the factory. The fact that business units managers are hierarchically under the global business manager promotes international 'learning' across units, since customers are global and their products are standard. Business unit managers, therefore, among other activities, need to support cross-border, inter-unit learning, since they are serving the same global customer. This arrangement has two functions. On the one hand, not only does it provide formal authority to BUMs to act across the network, but also it motivates BUMs to look for better global, rather than local, 'solutions' to a customer's demands. On the other hand, it facilitates KT processes, since it enables them to 'open doors' of different factories across the network in the search for optimal solutions for local/regional customers. Specifically, the matrix organisational structure facilitates the search for knowledge about product and production processes available in different parts of the global network (geographical units) and its utilisation at interand intra-regional units.

Secondly, the functional dimension, combined with the country dimension of the matrix organisational structure, also facilitates the diffusion of best practices in manufacturing processes. This is possible because matrix organisation structures are mirrored in all units across the world. The three Vice Presidents of operations (Americas, Asia and Europe) deliberately promote L\&KT between regional units. One of the mechanisms used for this is a regular meeting between country operations managers in order to discuss, set up and diffuse 'best practices' for each product. The meeting occurs once a year in one of the regional countries, while follow-up meetings occur regularly via video conference. While the formal face-to-face meeting serves to discuss ideas freely and to build personal relations among operations managers, the follow-up meetings are used to exchange ideas regarding processes that work, that do not work, unexpected barriers, and how they were overcome. In other words, followup meetings facilitate the diffusion of tacit forms of knowledge in local units supported by experienced overseas operations managers that have already implemented those practices.

In the case of the Brazilian unit, for example, the operations manager explained that there was a current transfer of a set of actions from the Guadalajara (Mexico) unit to the Betim (Brazil) unit for a specific assembly process. This form of benchmarking, 
according to the operations manager, favours the full utilisation of resources at each unit, since piecemeal components of whole processes can be compared and transferred, facilitating their local implementation. Because the Guadalajara plant had significantly more experience in a specific process, it was not difficult to decide the flow of knowledge. During the data collection process, inter-unit benchmarking on health \& safety practices was also observed. The functional and country dimensions of the matrix structure therefore allowed continuous 'internal benchmarking' both between functional areas and across countries. This international benchmarking process is enabled by the use of information systems that, among other uses, enable the measurement of key performance indicators across units manufacturing the same or similar products. Specifically, all managers in all units are aware of detailed performance indicators in different plants, making the comparison of plant performance a relatively easy exercise.

A key reason that makes possible the above mentioned flow of knowledge is, according to the operations manager, HQ's explicit promotion of positive personal relationships. This is a 'global practice' that nourishes personal relations, since BR understands that personal relations are crucial in facilitating L\&KT processes. In the case of the Brazilian unit, for example, end-of-year parties, Japanese-style open plan offices and common restaurant facilities for blue and while collar employees are some of the established socialization processes designed to assist personal relationshipbuilding.

An important part of the promotion of positive personal relations is the 'open doors' policy that is explicitly applied in the Brazilian unit. According to the operations manager, both formal and informal conversations are developed within an 'equal' environment, that is, staff members talk among themselves in equal conditions. This was witnessed by the interviewer during data collection. The latter contrasts, to a significant extent, with the high power distance that characterises Brazilian society in general (c.f Amado and Brasil, 1991). This suggests that, pushed by the higher needs of inter-unit collaboration, understanding and L\&KT demands, new behaviours are being developed in developing economies. The latter hints at the confirmation of what Hedlund (1986) has termed heterarchical tendencies, associated with global collaboration, while at the same time reinforcing hierarchical co-ordination. 


\section{Conclusion}

After acknowledging the impossibility of generalising case-study evidence, it is nevertheless possible to make a series of key points:

- GMP networks in the electronics industry, such as HQ, have high levels of product, technology, customer and organisational standardisation. This means that knowledge produced in one plant can be used in other plants. While significant parts of this knowledge are of an explicit nature, knowledge crucial for attaining high levels of competitiveness is of a tacit nature. This means that a combination of mechanisms for promoting L\&KT of either explicit forms of knowledge or tacit forms of knowledge have been developed.

- Specifically, it seems that while some of the L\&KT processes applied were adequate to deal with the highly standardised 'mass-production' face of GMP, other L\&KT processes were more adequate to cope with the 'service' dimension of electronics GMP.

- BR was able to combine a set of different L\&KT processes in order to cope with both explicit and tacit forms of knowledge.

- On the one hand, conventional forms of L\&KT used at BR seem to match what Buckey and Carter (2004) called 'additive complementarity', namely, the goal was to 'transfer' knowledge from one part to another part of the organization and knowledge involved was mostly explicit. On the other hand, complex complementarity also happened in the case of knowledge acquisition, by, for example, 'building experience'. The recognition by BR managers that some knowledge is site-specific and tacit in nature made possible the application of more sophisticated, lengthy and expensive learning mechanisms. 
- The use of organisational process to support L\&KT was clearly demonstrated in the case of BR. They were able to exploit positively mirrored matrix organisational structures to integrate dispersed manufacturing units by comparing and learning from one plant to another.

- Empirical evidence does not adhere to the potential 'problems' mentioned by the literature (Galbraith, 2000; Perrow, 1979; Child and Faulkner, 1998) that exist to share knowledge at the inter-organisational level. Conversely, the highly standardised nature of products, the fact that customers were global, and that the network belongs to one organisation with clear goals and processes, contributed to facilitate, rather than constrain, L\&KT activities between units.

- Empirical evidence also permitted the validation of some of the propositions made by the literature regarding key aspects that either support or constrain L\&KT processes. Case study data showed that the use of face-to-face socialisation mechanisms, the quality of communication flows (Nohria and Goshal, 1997), the existence of structural organisational mechanism such as training and clear goals (Lyles and Salk, 1996), the recognition of the importance of relational embeddedness for treating differently tacit forms of knowledge (Dhanaraj et.al., 2004), and the adequate choice of mechanism for transferring knowledge and learning (Hon and Nguyen, 2009), all contribute to the efficiency of L\&KT processes.

- The importance of the relationship between L\&KT process and organisational processes noted by Foss and Pedersen (2004) seems to be important to explain what can be qualified as successful deployment of L\&KT processes. The evidence showed a connection between BR's L\&KT mechanisms and the matrix organisational structure. While the first were composed of specific L\&KT mechanisms, the second was a deliberate 'structural' approach to support and complement the former. We believe that without the support of the matrix organisational structure, the efficiency of the established L\&KT mechanisms would have not been the same. 
In considering these issues and conclusions, then applying them to the global transfer of global modular production technology, it is clear that the BR case-study provides many object lessons that other BRIC economies might learn when participating in this system. Of course, it will be essential to consider whether localised adaptation will be necessary, but the Brazilian case demonstrates that successful implementation is possible, as long as the appropriate learning mechanisms have been developed and applied.

\section{References}

Ancori, B., Bureth, A., \& Cohendet, P. 2000. The economics of knowledge: The debate about codification and tacit knowledge. Industrial and Corporate Change, 9(2): 255-287.

Amado, G. and Brasil, H. (1991) Organizational Behaviours and Cultural Context: The Brazilian 'Jeitinho', International Studies of Management and Organization, 21(3)

Amann E. and Baer W. (2002) Neoliberalism and its consequences in Brazil, Journal of Latin American Studies, 34, 945-959

Argote, L. and Ingram, P. 2000. Knowledge transfer: A basis for competitive advantage. Organizational Behavior and Human Decision Processes, 82(1): 150-169.

Argote, L. and Darr, E. 2002. Repositories of knowledge in franchise organizations. In G. Nelson R. \& Winter S. (Eds.), The nature and dynamics of organizational capabilities: 51-68. New York: Oxford University Press.

Bartmess, A. and Cerny, K. (1993) Building competitive advantage through a Global Network of Capabilities, California Management Review, Winter.

Bell, R.M. (1984) 'Learning' and the Accumulation of Industrial Capacity in Developing Countries, In Fransman M. \& King, K. (Eds.) Technological Capacity in the Third Word, Macmilan, London.

Bell, R. M. and Albu, M. (1999) Knowledge systems and technological dynamism in industrial clusters in developing countries, World Development, 27(9): 1715-1734.

Berger S. and Dore R. (1999) National Diversity and Global Capitalism, Cornell University Press, Ithaca. 
Bjorkman, I., Barner-Rasmusen, W. and Li, L. (2004) Managing knowledge transfer in MNC: A comprehensive test of headquarters control mechanisms, Journal of International Business Studies, 35.

Buckley, P. and Casson, M. (1976) The future of the multinational enterprise, Macmillan, London.

Buckley, P. and Carter, M. (2004) A formal analysis of knowledge combination in multinational enterprises, Journal of International Business Studies, 35:371-384.

Buckley, P. and Carter, M. (1999) Managing cross-border complementary knowledge, International Studies of Management \& Organization, 29(1): 80-104.

Chandler, A.D. Jr. (1990), Scale and Scope: The Dynamics of Industrial Capitalism, Harvard University Press, Cambridge.

Child, J. and Faulkner, D. (1998) Strategies of Co-operation, Oxford University Pres, London.

Dahlman C. and Frischtak (1993) National Systems of innovation supporting technical advance in industry: The Brazilian Experience, World Bank, unpublished paper.

Davenport, T., \& Prusak, L. (1998) Working knowledge: How organizations manage what they know, Boston: Harvard Business School Press.

Dhanaraj, C., Lules, M., Steenma, H. K., \& Tihanyi, L. 2004. Managing tacit and explicit knowledge transfer in IJV: The role of relational embeddedness and the impact on performance, Journal of International Business Studies, 35: 428-442.

Dixon, N. 2000. Common knowledge. Boston: Harvard Business School Press.

Dougherty, D. (1999) Organizing for innovation, in Clegg., S., Hardy, C., and Nord., W. (Eds.) Managing Organizations, Sage, London, p. 174-89.

Evangelista, F. and Hau, N. (2009) Organizational context and knowledge acquisition in IJV: An empirical study, Journal of Word Business, 44: 63-73.

Ferdows K. (1997) Making the most of foreign factories, Harvard Business Review, march-April.

Foss, N. and Pedersen, T. (2004) Organizing knowledge processes in the multinational corporation: an introduction, Journal of International Business Studies, 35: 340-349.

Fruin M. (1997) Knowledge Works, Oxford University Press, New York.

Galbraith J. (2000) Designing the global corporation, Jossey-Bass, San Francisco 
Guzman, G. and Lopez D. (2000) Contract Manufacturing in Brazil: Challenges and opportunities of a new production model, in Fleury, A., Yoshizaki, H., Guimaraes, L.B. and Ribeiro, J.L. (EDs.) Building Competencies for International Manufacturing, FEENG, Porto Alegre, Brazil.

Guzman, G. (2003) Inside modular production networks: 'soft operational issues' in building factory competitiveness, Integrated Manufacturing Systems, Vol.14, N.1, pp. 6-15.

Guzman, G., and Wilson, J. (2005a) The 'soft' dimension of organizational knowledge transfer. Journal of Knowledge Management, 9(2): 59-74.

Guzman, G. and Wilson, J. (2005b) Organizational Knowledge Transfer in Modular Production Networks: experiences from Brazil, in Neto, J. A. (ed.) Inter Organizational Networks, Atlas, Sao Paulo (in Portuguese).

Hamel, G. and Prahalad, C. (1994), Competing for the future, Harvard Business Review Press, Boston, Massachusetts.

Hansen, M. 1999. The search-transfer problem: The role of weak ties in sharing knowledge across organization subunits. Administrative Science Quarterly, 44: 82111.

Hedlund, G. (1986), 'The hypermodern MNC - a heterarchy?', Human Resource Management, 25, 1, 9-34.

Hong, J. and Nguyen, T. (2009) Knowledge embeddedness and the transfer mechanism in multinational corporations, Journal of Word Business, doi:10.1016/j.jwb.2009.01.001

Katz J. (2000) Cambios en la estructura y comportamiento de la infraestructura productiva en America Latina en los anos 1990s, CEPAL, Serie Desarrollo Productivo 65, Santiago de Chile.

Khurana, A. (1999), Managing complex production processes, Sloan Management Review, 40(2): 47-55.

Kotabe, M., Dunlap-Hinker, D., parente, R. And Mishra, H. (2007) Determinants of cross-national knowledge transfer and its effect on firm innovation, Journal of International Business Studies, 38: 259-282

Leonard, D. (1995) Wellsprings of knowledge, Harvard Business School Pres, Boston, MA.

Lillrank P. (1995) The transfer of management innovations from Japan, Organizational Studies, Vol.16, N. 6, pp. 971-990

Lyles, M. and Salk, J. (1996) Knowledge acquisition from foreign parents in international joint ventures: an empirical examination in the Hungarian context, Journal of International Business Studies, 27: 877-903. 
Macharzina K., Oesterle M-J, Brodel D. (2000) Learning in Multinationals, in Dierkes M., Antal A., Child J., Nonaka I. (Eds.) Handbook of Organizational Learning and Knowledge, Oxford University Press, London

March, J.G. and Simon, H.A. (1958) Organizations, Wiley, New York

Olivera, F. 2000. Memory systems in organizations: An empirical investigation of mechanisms for knowledge collection, storage and access, Journal of Management Studies, 37(6): 811-832.

Orlikowski, W. 2002. Knowing in practice: Enacting a collective capability in distributed organizing. Organization Science, 13(3): 249-274.

Perrow, C. (1979) Complex Organisations: A Critical Essay, Scott Foresman, Glenview, ILL.

Pick, A. (2009) Race to Brazilian market begins for CMs, E.M. Snow

Polanyi M. (1983) The Tacit Dimension, Peter Smith, Gloucester, Mass.

Prencipe, A., \& Tell, F. 2001. Inter-project learning: Processes and outcomes of knowledge codification in project-based firms. Research Policy, 30: 1373-1394.

Saliola, F. and Zanfei, A. (2009) Multinational firms, global value chain and the organization of knowledge transfer, Research Policy, 38: 369-381.

Simonin, B. (2004) An empirical investigation of the process of knowledge transfer in international strategic alliances, Journal of International Business Studies, 35: 407427.

Shi, Y. and Gregory, M. (1998) International manufacturing networks - to develop global competitive capabilities, Journal of Operations Management, 16:195-214.

Suares, F., Cusumano, M. and Hine, C. (1995) An empirical study of flexibility in manufacturing, Sloan Management Review, Fall.

Stacey, R.D. (1996) Strategic Management and Organisational Dynamics, Pitman Publishing, London

Sturgeon T. (2002) Modular production networks: A new American model of industrial organization, Industrial and Corporate Change, 11(3).

Tsoukas, H. 2005. Do we really understand tacit knowledge? In Easterby-Smith, M \& Lyles, M. (Eds.), The Blackwell handbook of organizational learning and knowledge management: 410-427. Oxford, U.K.: Blackwell.

Macharzina K., Oesterle M., Brodel D. (2000) Learning in multinationals, In Dierkes M., Antal A., Child J. and Nonaka I. (Eds.) Handbook of organizational learning and knowledge, Oxford University Press, London. 
Nohria, N. and Ghoshal, S. (1997) The differentiated network, Jossey-Bass, San Francisco.

Minbaeva, D. (2007) Knowledge transfer in Multinational Corporations, Management International Review, 47(4): 567-593.

Mudambi, R. and Navara, P. (2004) Is knowledge power? Knowledge flows, subsidiary power and rent seeking within MNCs, Journal of International Business Studies, 35: $\mathrm{xxx}$

Walsh, J. and Ungson, G. (1991) Organizational memory, Academy of Management Review, 16:57-90.

Wenger, E. (1998) Communities of practice: Learning, meaning and identity. New York: Cambridge University Press.

Westney. E. (1999) Organizational theory perspectives on cross-border transfer of organizational patterns, in Liker, J., Fruin, M. and Adler, P. (Eds.) Remade in America, Oxford University Pres, New York.

Wood T. and Caldas J.C.(2002) "Adopting imported managerial expertise in developing countries; The Brazilian experience”, Academy of Management Executive, 16(2).

Yin R. (1981) "The case study crisis- some answers", Administrative Science Quarterly, Vol. 26, march, pp.423-35.

Zarifian, P. (1999) El modelo de competencia e los sistemas produtivos, Papeles de la oficina tecnica, OIT, Cinterfor.Montevideo.

Zollo, M., \& Winter, S. 2002. Deliberate learning and the evolution of dynamic capabilities. Organization Science 13(3): 339-352. 